say which of the two views is supported by the discovery of the same species in London. Mr. Morison assures me that no plants have been introduced into his garden for at least three years. Probably the worm will be found in other parts of London, and it would be worth while to search carefully for it at Kew.

It will be remembered that another land Planarian, Placocephalus (Bipalium) kevense, was first found at $\mathrm{KeW}$ and is admittedly exotic, having since been found in many parts of the world, especially in the neighbourhood of botanic gardens, being distributed, doubtless, with plants. There is, however, one undoubtedly indigenous British land Planarian, Rhyncho. demus terrestris, which differs from $R$. Scharffi in its grey colour and much smaller size. This worm is rarely met with unless carefully searched for, and it is quite possible that $R$. Scharffi also will yet be found in situations less open to suspicion than Dublin and London gardens. I hope that the publication of this letter may lead to such a discovery. (King's College), April 28

\section{Method of Cutting Sections of Cotton Hairs.}

No satisfactory method of cutting sections of cotton hairs and similar material appears to have been published; the technique recommended by Balls ("Development and Properties of Raw Cotton," p. I76) is open to the objection that the hairs pull away from the wax at the cutting surface, thus losing the rigidity which is essential for good sections, and attempts made to remedy this by coating the hairs with a paraffin-wax different from that of the main embedding mass did not produce any marked increase in adhesion; while embedding in celloidin or cellulose acetate gave very unsatisfactory results by reason of the contraction and distortion of the hairs.

The method finally evolved was modified from that of Breckner (Z. f. Wiss. Mikr., vol. xxv., p. 29, 1909), and is dependent on the use of a coating of celloidin to procure greater adhesion to the wax embedding mass. The cotton, fixed in a small wire frame for greater convenience, is "wetted out" with absolute alcohol and placed in a dilute syrupy solution of celloidin in alcohol-ether, which is allowed to evaporate to half or a third of its volume. The material is then taken out, squeezed between the fingers to remove excess of fluid, and placed in a chloroform solution of paraffin-wax for two hours, after which the cotton is cut from the frame, transferred to paraffin, and quickly embedded. Sections should be cut without delay, as the material appreciably toughens within twenty-four hours, but blocks can be stored in water for an indefinite time if a trace of antiseptic be added.

Cutting should preferably be done on a sliding microtome, but $5 \mu$ sections have been made without difficulty on a Leitz "Minot," with the knife oblique. A useful way of dealing with the sections when cut is to dissolve away the wax and celloidin in alcoholether and centrifuge. If the sections are thin enough a very large proportion will be the right way up when spread upon the slide.

Since this letter was written a description of a method for embedding cotton varns and fabrics has been published in the Journal of the Textile Institute (April, I92I) by Willows and Alexander. Opportunity has not so far arisen for comparative tests of the two techniques.

H. J. Denham.

Botanical Laboratory, British Cotton-Industry Research Association, Shirley Institute, Didsburv. April 20.

$$
\text { NO. } 2688 \text {, VOL. IO7]. }
$$

\section{An Unknown Organism in Flint.}

A PrT dug in my garden here exposed about $12 \mathrm{ft}$. of the usual Thames Valley gravels and sands, at which depth (approximately) what local excavators call "shingle" was reached. This is composed chiefly of flint-stones mixed with. sand, and lacks the binding properties of the gravel above. The rule is to stop digging for gravel when the "shingle" appears.

Pending a detailed description which will be given elsewhere, I may say that the gravels consist of various types of flint and different kinds of sandstones, together with quartzites, vein quartz, Lydian stone, chert with spicules, fragments of sarsen, etc., some of these being of sufficient interest to warrant the cutting of micro-sections. During the last few vears some hundreds of these stones have been washed and examined by the platyscopic lens and microscope for surface features.

On one of the flint fragments I discovered a minute fossil organism resembling some form of insect, the like of which, so far as I can ascertain, has not been seen in flint before. There is a head with curious projections on either side, club-shaped antennæ which

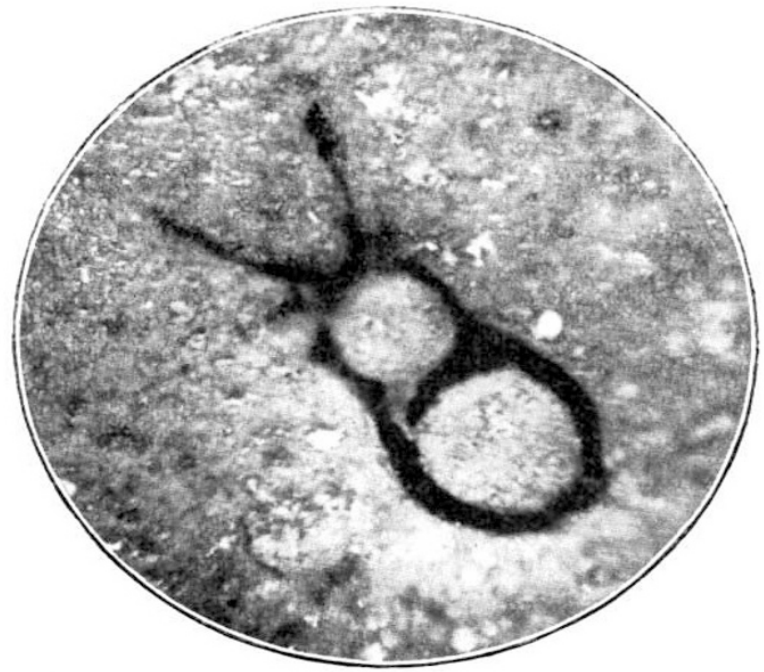

FIG. 1.-Photomicrograph of an apparent organism in flint. Magnification, about 30 diameters.

are segmented, a thorax, and an abdomen, but no legs are visible.

The chitinous parts appear to be silicified, and show up well when moistened under a low power, but there are reasons why it is a very difficult object to photograph satisfactorily in the ordinary way. The one I enclose was kindly taken for me by $\mathrm{Mr}$. A. Cornell with a super-microscope, the magnification being about 30 diameters (Fig. I).

It is difficult to understand how an organism of such delicate structure could have been preserved in flint unless its entombment occurred while the flint was in a colloid condition. If any reader of NATURE can say what the organism is, I shall feel grateful.

\section{Strawberry Hill, Middlesex}

$$
\text { C. Carus-Wilson: }
$$

\section{Ocean Tides.}

WHILE not considering myself qualified to question the gain to scientific knowledge on the theoretical side which might accrue from the investigation of ocean tides, such as Prof. Proudman suggested in his article in NATURE of April 7, p. 176 , I yet venture the opinion 